\title{
Article \\ A Disc-Type High Speed Rotary Ultrasonic Motor with Internal Contact Teeth
}

\author{
Jianmin Qiu ${ }^{1}$, , Ying Yang ${ }^{1, *}$, Xin Hong ${ }^{1}$, Piotr Vasiljev ${ }^{1,2}$, Dalius Mazeika ${ }^{1,3}$ and Sergejus Borodinas ${ }^{1,4}$ \\ 1 State Key Laboratory of Mechanics and Control of Mechanical Structures, College of Aerospace Engineering, \\ Nanjing University of Aeronautics and Astronautics, 29 Yudao Street, Nanjing 210016, China; \\ qiujianmin@nuaa.edu.cn (J.Q.); hongxin@comac.cc (X.H.); piotr.vasiljev@vdu.lt (P.V.); \\ dalius.mazeika@vgtu.lt (D.M.); sergejus.borodinas@vgtu.lt (S.B.) \\ 2 Education Academy, Vytautas Magnus University, K. Donelaicio Str. 58, LT-44248 Kaunas, Lithuania \\ 3 Department of Information Systems, Vilnius Gediminas Technical University, Sauletekio Avn. 11, \\ LT-10223 Vilnius, Lithuania \\ 4 Department of Applied Mechanics, Vilnius Gediminas Technical University, Sauletekio Avn. 11, \\ LT-10223 Vilnius, Lithuania \\ * Correspondence: yingyang@nuaa.edu.cn; Tel.: +86-025-84891937
}

check for updates

Citation: Qiu, J.; Yang, Y.; Hong, X.; Vasiljev, P.; Mazeika, D.; Borodinas, S. A Disc-Type High Speed Rotary Ultrasonic Motor with Internal Contact Teeth. Appl. Sci. 2021, 11, 2386. https://doi.org/10.3390/ app11052386

Academic Editor: Nicola Pio Belfiore

Received: 19 January 2021

Accepted: 2 March 2021

Published: 8 March 2021

Publisher's Note: MDPI stays neutral with regard to jurisdictional claims in published maps and institutional affiliations.

Copyright: (c) 2021 by the authors. Licensee MDPI, Basel, Switzerland. This article is an open access article distributed under the terms and conditions of the Creative Commons Attribution (CC BY) license (https:// creativecommons.org/licenses/by/ $4.0 /)$.

\begin{abstract}
This paper presents a disc-type ultrasonic piezoelectric motor, which is designed for micro flying vehicles. It provides a high output rotation speed under low operating voltage, compared with common piezoelectric devices, by employing a "contact teeth" wave transmission structure. The ultrasonic motor (USM) consists of a trimorph disc stator, with triple internal contact teeth, a shaft and two hemispheric hard-wearing rotors. The operating principle of the USM is based on the superposition of the in-plane $\mathrm{B}_{03}$ vibration mode of the trimorph disc, and the first longitudinal vibration of the contact teeth. An optimization method of the stator structure parameters was proposed and validated by numerical modeling. The diameter and thickness of the stator are $20 \mathrm{~mm}$ and $1 \mathrm{~mm}$, respectively. A prototype with the weight of $2 \mathrm{~g}$ was made for this experimental test. The optimal frequency of the excitation signal and the preload force are $98.5 \mathrm{kHz}$ and $0.5 \mathrm{~N}$, respectively. The minimum operating voltage was tested under $7.5 \mathrm{~V}$ and reached the speed of $225 \mathrm{rpm}$, and the maximum unloaded rotational speed of the USM reached $5172 \mathrm{rpm}$ when $30 \mathrm{~V}$ driving voltage was applied. The maximum lifting force generated by this USM was measured as $46.1 \mathrm{mN}$, which is 2.35 times bigger than its weight.
\end{abstract}

Keywords: ultrasonic motor; disc-type rotary motor; high speed; low driving voltage

\section{Introduction}

Today, the demand for small-sized and high-performance motors [1,2] is increasing greatly in high-end equipment such as microelectronics, micro robots and micro air vehicles (MAVs). Especially, rotary motors are rapidly developing in recent years due to growing interest in MAVs. MAVs are widely used in air surveillance, emergency rescue, target tracking, disaster warning and so on [3-5]. The MAV possesses some advantages such as small size, light weight, low noise, strong concealment and agility [6,7]. At present, the DC motor is widely used as the driving motor for MAVs [8,9]. However, as the size of the motor decreases, the Joule heat loss of the motor rapidly increases, and thus, the efficiency of the DC motor is greatly reduced [3], which has become an important limiting factor of the MAV's endurance time. By contrast, the ultrasonic motor (USM) utilizes the inverse piezoelectric effect and contact friction to convert electrical energy into mechanical energy, which is a more efficient driving method at reduced size. It also possesses many attractive features, such as a compact structure, fast response (microsecond level), high holding torque and high positioning accuracy [10,11].

Some of the existing small-sized rotary USMs have excellent output performance. S. Borodinas et al. designed a compact size coplanar trimorph rotary piezoelectric motor for 
high-speed applications [12]. The diameter of the trimorph disc is $5 \mathrm{~mm}$, and the total thickness is $0.8 \mathrm{~mm}$. A prototype was manufactured, which can reach $3850 \mathrm{rpm}$ at $80 \mathrm{~V}_{\mathrm{pp}}$. L. Wang et al. introduced a rotary USM, based on the out-of-plane flexural vibration mode. Four different harmonic signals, with a phase shift of $\pi / 2$, were used to excite the stator. The diameter of the stator is $22 \mathrm{~mm}$, and it can obtain $5000 \mathrm{rpm}$ when the driving voltage is $350 \mathrm{~V}_{\mathrm{pp}}$ [13]. T. Mashimo proposed a micro ultrasonic motor with a cubic millimeter stator, and the prototype can obtain $2500 \mathrm{rpm}$ at $98 \mathrm{~V}_{\mathrm{pp}}$ [14]. X. Chu et al. used vibration mode $\mathrm{B}_{11}$ to design a disk-pivot structure micro piezoelectric actuator, which can obtain 10,071 rpm when driving voltage is $100 \mathrm{~V}_{\mathrm{pp}}$ [15], and the starting voltage can reach $30 \mathrm{~V}_{\mathrm{pp}}$. Apparently, the high-speed rotary USMs mentioned above have potential ability to drive MAVs, but their driving voltage is too high for the micro drive system. High driving voltage acts as a restriction for minimizing the size of the USM. Therefore, a bulkier USM will limit the load capacity and endurance time of an MAV. Hence, reducing the driving voltage of micro-sized USMs should be the priority when considering use of these for driving the motors of MAVs. Compared with single layer piezoelectric ceramics, the multilayer piezoelectric ceramics as energy conversion units is the highly effective way for reducing the driving voltage of USMs, which driving voltage is approximately inversely proportional to the number of layers of the same thickness. However, when it comes to high frequency application, dielectric loss of the piezoelectric stack will significantly enhance, and so does the dissipated heat. After a long period of continuous work, the accumulated heat causes the USM's performance to plummet. In general, it is difficult to find a proper piezoelectric stack that can be used in a USM specially designed for MAVs. Therefore, new motors with novel principles must be developed to solve the above-mentioned problems.

A high-speed disc-type coplanar ultrasonic piezoelectric motor driven by low voltage is proposed in this paper. The principle of the motor is described, and numerical simulation and optimization were performed. The optimal dimensions of the multi-contact teeth stator have been calculated. An experimental study was performed after manufacturing a prototype. The results of this experimental investigation and numerical analysis are discussed, and they are in good agreement. Motor performance and lifting characteristics after mounting a propeller were tested and analyzed.

\section{Design and Operating Principle of the Ultrasonic Motor}

The components of the disc-type USM are shown in Figure 1. The USM consists of a rotation shaft, a fastening sleeve, a spring, two hemispherical rotors, a fastening screw, two piezoelectric ceramic rings and a titanium disc with three internal contact teeth. Schematics of the stator and rotor are shown in Figure 2. The stator is a trimorph disc with three internal contact teeth, which are used to excite the rotors to rotate under its $\mathrm{B}_{03}$ vibration mode. The chamfers at the bottom of the contact teeth are designed to reduce stress concentration. Two piezoceramic rings are glued on both sides of the titanium disc. The thickness of the titanium disc is $0.5 \mathrm{~mm}$, while thickness of both the piezoelectric ceramic rings is $0.2 \mathrm{~mm}$. The polarization direction of the piezoelectric ceramic rings is shown in the side view of the stator. The upper and lower surfaces of the stator are in contact with two rotors, and the preload is obtained by the spring. The rotor in contact with the lower surface of the stator is fixed onto the shaft, and the other one can freely slide on the shaft. Both rotors were made of alumina, and their dimensions are shown in Figure 2.

The excitation scheme of the stator is shown in Figure 3. A sine wave electrical signal is applied to the piezoelectric ceramic rings through the electrodes, and the metal part is connected to ground. This configuration is used to excite radial oscillation of the stator. 


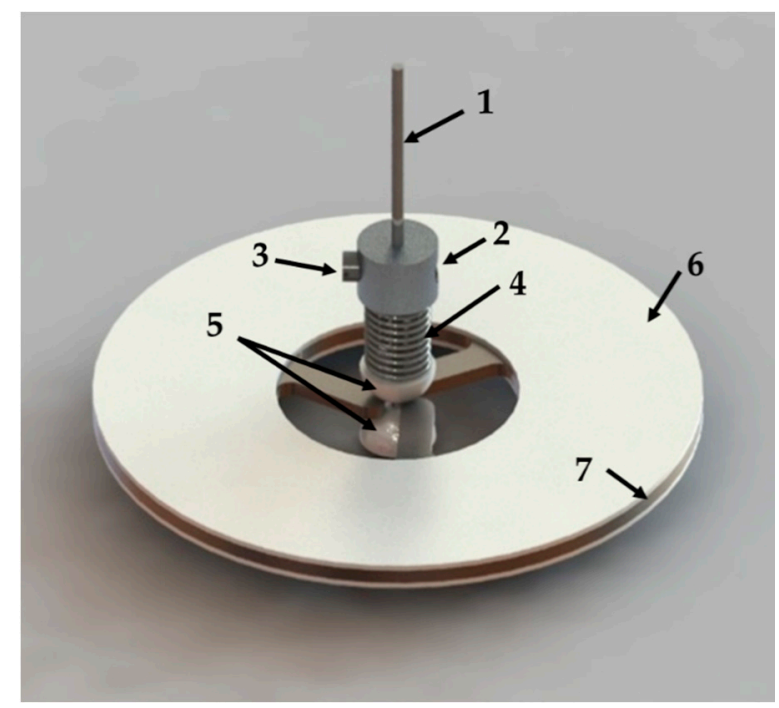

Figure 1. Design of the disc-type ultrasonic motor: (1) rotational shaft; (2) fastening sleeve; (3) fastening screw; (4) spring; (5) rotors; (6) piezoelectric ceramic ring; (7) titanium disc.

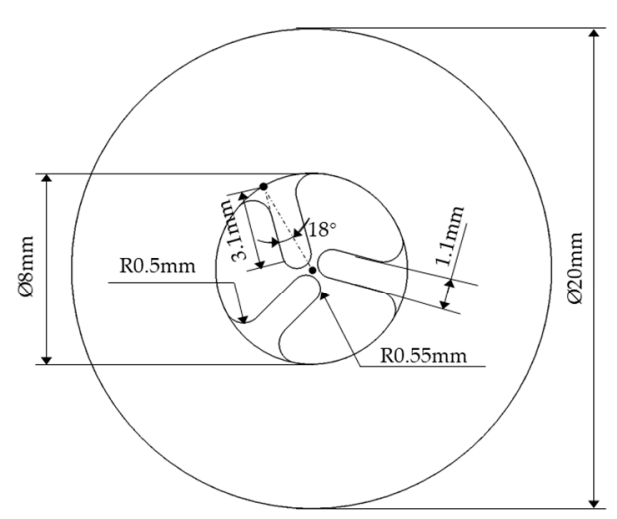

Top view of stator

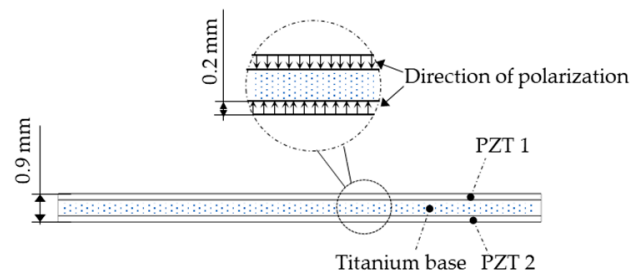

Side view of stator

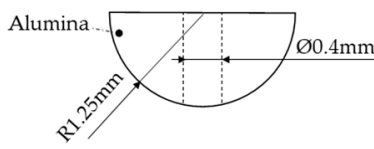

Side view of rotor

Figure 2. Schematics of stator and rotor.

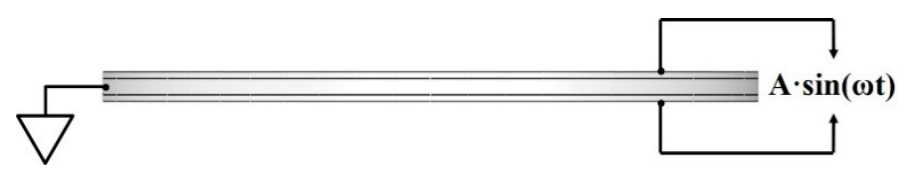

Figure 3. Excitation scheme of the stator.

The actuating principle of the motor is mainly based on a "push-pull" motion [12] of its contact teeth, excited by the $\mathrm{B}_{03}$ vibration mode of the stator (Figure 4 ). It requires the contact teeth to obtain large longitudinal displacement under resonate mode. The contact teeth and the rotor have different frictional force in the push and pull stage, leading to the difference in the rotating moment. The rotating moment in the push stage is bigger than in the pull stage, and their relationship can be written as follow:

$$
\left|\int_{0}^{\theta_{1}} M_{1}\right|>\left|\int_{0}^{\theta_{1}-\theta_{2}} M_{2}\right|
$$

where $M_{1}, M_{2}, \theta_{1}$ and $\theta_{2}$ represent the rotating moment in the push stage, the rotating moment in the pull stage, the rotation angle in the push stage, and the rotation angle in the pull stage, respectively. Thus, after accumulating each period of rotation angle, the rotor rotates along the pushing moment direction. 


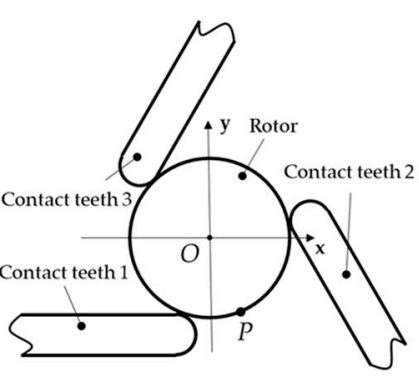

(a) Initial position

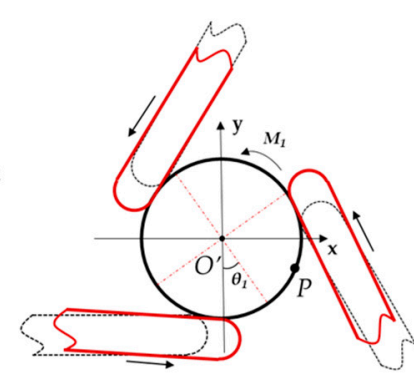

(b) Push stage

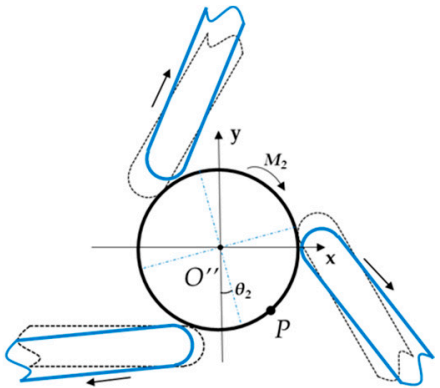

(c) Pull stage

Figure 4. Actuating principle of the motor.

\section{Numerical Modeling and Results}

The first step of numerical modeling is to obtain the characteristic frequencies and modal shapes of the stator by finite element method (FEM). A numerical simulation of the stator was performed by using FEM software COMSOL Multiphysics. A finite element model of the stator is shown in Figure 5a. The model contains a titanium layer and two piezoelectric ceramic rings. An adhesive layer was neglected in the model. The initial inner and outer diameters of the titanium alloy plate were set to $8 \mathrm{~mm}$ and $20 \mathrm{~mm}$, respectively. The length, width and angle of the contact teeth were set to $3.25 \mathrm{~mm}, 1.2 \mathrm{~mm}$ and $18^{\circ}$ initially. The stator was meshed by three-dimensional standard tetrahedral finite elements. After several iterations, a complete finite element mesh was defined and it contained 57,905 domain elements, 21,244 boundary elements and 1132 edge elements. The material properties of titanium alloy and piezoelectric ceramics are listed in Table 1. As shown in Figure $5 \mathrm{~b}$, the $\mathrm{B}_{03}$ modal shape of the initial dimensions is calculated at the frequency of $98.737 \mathrm{kHz}$. Figure $5 \mathrm{~b}$ with color legend represents the value of total displacement, and it can be observed that the total displacement of the contact teeth fits well with the principal design requirement of this modal shape.

Table 1. Properties of the materials.

\begin{tabular}{ccc}
\hline Material Property & $\begin{array}{c}\text { Titanium Alloy } \\
\text { (Ti6A4V) [12] }\end{array}$ & $\begin{array}{c}\text { Piezoelectric Ceramics } \\
\text { PIC151 [16] }\end{array}$ \\
\hline $\begin{array}{c}\text { Density, } \mathrm{kg} / \mathrm{m}^{3} \\
\text { Young's modulus, } \mathrm{N} / \mathrm{m}^{2}\end{array}$ & 4450 & 7800 \\
Poisson's coefficient & $110 \times 10^{9}$ & $7.6 \times 10^{10}$ \\
Isotropic structural loss factor & 0.34 & - \\
Relative permittivity & 0.025 & - \\
& - & $\varepsilon_{33} \mathrm{~T} / \varepsilon_{0}=1200$ \\
$\varepsilon_{11}^{\mathrm{T}} / \varepsilon_{0}=1500$ \\
Elastic compliance coefficient $\left(10^{-12} \mathrm{~m}^{2} / \mathrm{N}\right)$ & - & $\mathrm{S}_{11} \mathrm{E}=15.00$ \\
Elastic stiffness coefficient $\mathrm{c}_{33} \mathrm{D}, \mathrm{N} / \mathrm{m}^{2}$ & - & $\mathrm{S}_{33} \mathrm{E}=19.00$ \\
Piezoelectric constant $\mathrm{d}_{33}\left(10^{-12} \mathrm{~m} / \mathrm{V}\right)$ & - & $1.6 \times 10^{10}$ \\
Piezoelectric constant $\mathrm{d}_{31}\left(10^{-12} \mathrm{~m} / \mathrm{V}\right)$ & - & 225 \\
Piezoelectric constant $\mathrm{d}_{15}\left(10^{-12} \mathrm{~m} / \mathrm{V}\right)$ & - & -97 \\
\hline
\end{tabular}

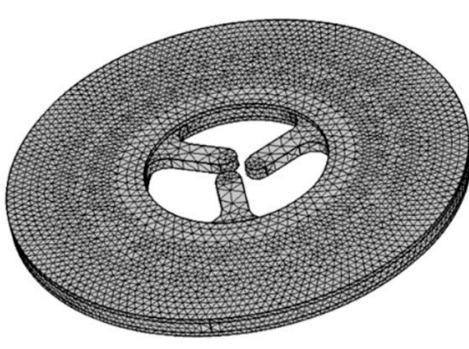

(a)

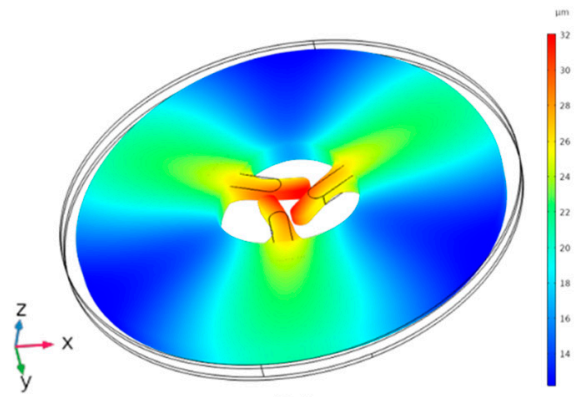

(b)

Figure 5. (a) Finite element method (FEM) mesh of the stator; (b) $\mathrm{B}_{03}$ mode shape of the stator. 
After confirming the working mode of the stator, the next step of optimization was to find the optimal dimension parameters of the stator, to allow the contact point " $\mathrm{x}$ " (Figure 6) of the stator to gain maximum amplitude in this working mode. Frequency domain analysis method was chosen for use in the process of optimization. Harmonic response analysis was performed to calculate amplitudes of the contact points.

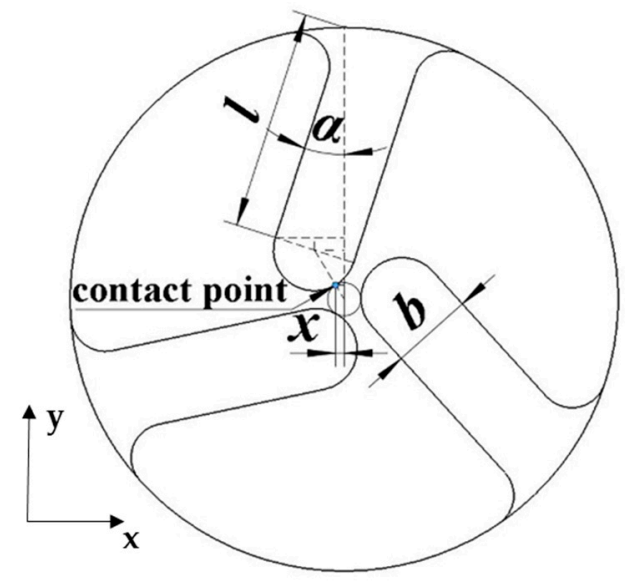

Figure 6. Contact point between stator and rotor.

The amplitudes of the contact point depend on the inner and outer diameters of the stator, as well as the length, width and angle of the contact teeth. Because of the scalability of the USM, and considering the limitations of size and complexity of manufacturing, the inner and outer diameters of the stator were chosen to be $8 \mathrm{~mm}$ and $20 \mathrm{~mm}$, the same as the ceramic ring. Thus, the length, width and angle of the contact teeth were optimized to find the maximum oscillation amplitude of the contact point. The formulas of this optimizing problem are listed below:

$$
u_{t o t}^{\max }=\sqrt{u^{2}{ }_{x}(b, l, \alpha)+u^{2}(b, l, \alpha)}
$$

Subjected to

$$
\begin{aligned}
b_{\min } & \leq b \leq b_{\max } \\
l_{\min } & \leq l \leq l_{\max } ; \\
\alpha_{\min } & \leq \alpha \leq \alpha_{\max } \\
f_{\min } & \leq f \leq f_{\max } .
\end{aligned}
$$

where $u_{\text {tot }}$ is oscillation amplitude of the contact point, $b, l$ and $\alpha$ are the width, length and angle of the contact teeth, respectively, $b_{\min } / b_{\max }, l_{\min } / l_{\max }$ and $\alpha_{\min } / \alpha_{\max }$ are the minimum/maximum limits of the width, length and angle, $f$ is the resonant frequency of the stator and $f_{\min } / f_{\max }$ are the minimum/maximum limits of the frequency. As is shown in Figure 6, the horizontal distance between the contact point and the central axis $x$ is related to the three variables, i.e., $b, l$ and $\alpha$. The similar triangle theorem is used to solve this plane analytic geometry problem, and the distance $x$ is described as follows: Equation (7) is used to determine the position of the contact point when different length, width and angle of the contact teeth are applied:

$$
x=\frac{\left(l \cdot \sin \alpha-\frac{b}{2} \cdot \cos \alpha\right) \cdot\left[\sqrt{\left(l \cdot \sin \alpha-\frac{b}{2} \cdot \cos \alpha\right)^{2}+\left(4-l \cdot \cos \alpha-\frac{b}{2} \cdot \sin \alpha\right)^{2}}-\frac{b}{2}\right]}{\sqrt{\left(l \cdot \sin \alpha-\frac{b}{2} \cdot \cos \alpha\right)^{2}+\left(4-l \cdot \cos \alpha-\frac{b}{2} \cdot \sin \alpha\right)^{2}}}
$$

To initiate the FEM analysis, the scan range should be determined, based on the dimension parameters of the contact teeth. The scanning range of each simulation parameter 
set is shown in Table 2. Scanning interval of frequency was determined by calculating the characteristic frequency of the stator $\mathrm{B}_{03}$ mode, which corresponds to the two groups of critical sizes $\left(l_{\min }=2.8 \mathrm{~mm}, b_{\min }=0.8 \mathrm{~mm}, \alpha_{\min }=15 ; l_{\max }=3.2 \mathrm{~mm}, b_{\max }=1.2 \mathrm{~mm}\right.$, $\alpha_{\max }=30^{\circ}$ ) in the dimension parameters value range. Characteristic frequencies of $\mathrm{B}_{03}$ mode corresponding to the critical sizes were calculated at $98.5 \mathrm{kHz}$ and $101.5 \mathrm{kHz}$, respectively. Thus, the scanning interval of frequency was set from $98 \mathrm{kHz}$ to $102 \mathrm{kHz}$ with the scanning step of $100 \mathrm{~Hz}$. Frequency domain simulations were performed for the 375 combinations of the dimension parameter variables, which are listed in Table 2.

Table 2. FEM parameter scan list.

\begin{tabular}{ccc}
\hline Parameter & Value & Scanning Step \\
\hline External diameter, $\mathrm{R}$ & $20 \mathrm{~mm}$ & - \\
Internal diameter, $\mathrm{r}$ & $8 \mathrm{~mm}$ & - \\
Contact teeth length, $l$ & $(2.80 \mathrm{~mm}, 3.20 \mathrm{~mm})$ & $0.1 \mathrm{~mm}$ \\
Contact teeth width, $b$ & $(0.8 \mathrm{~mm}, 1.2 \mathrm{~mm})$ & $0.1 \mathrm{~mm}$ \\
Contact teeth width, $\alpha$ & $\left(15^{\circ}, 30^{\circ}\right)$ & $1^{\circ}$ \\
Frequency of applied voltage & $(98 \mathrm{kHz}, 102 \mathrm{kHz})$ & $0.1 \mathrm{kHz}$ \\
\hline
\end{tabular}

Boundary conditions of the model used for the optimization were set. The mechanical boundary of the stator was set to be free. The excitation scheme of the electrodes was used, as shown in Figure 3. The voltage amplitude of $20 \mathrm{~V}_{\mathrm{pp}}$ was applied on the electrodes, and the frequency range was set from $98 \mathrm{kHz}$ to $102 \mathrm{kHz}$ with a frequency scan step of $0.1 \mathrm{kHz}$. $2 \mathrm{D}$ plots of the amplitude of contact points in $\mathrm{B}_{03}$ mode vary with length, width, and angle of contact teeth are shown in Figure 7. The color legend of the plot shows the value of the amplitude in the order of micrometers.
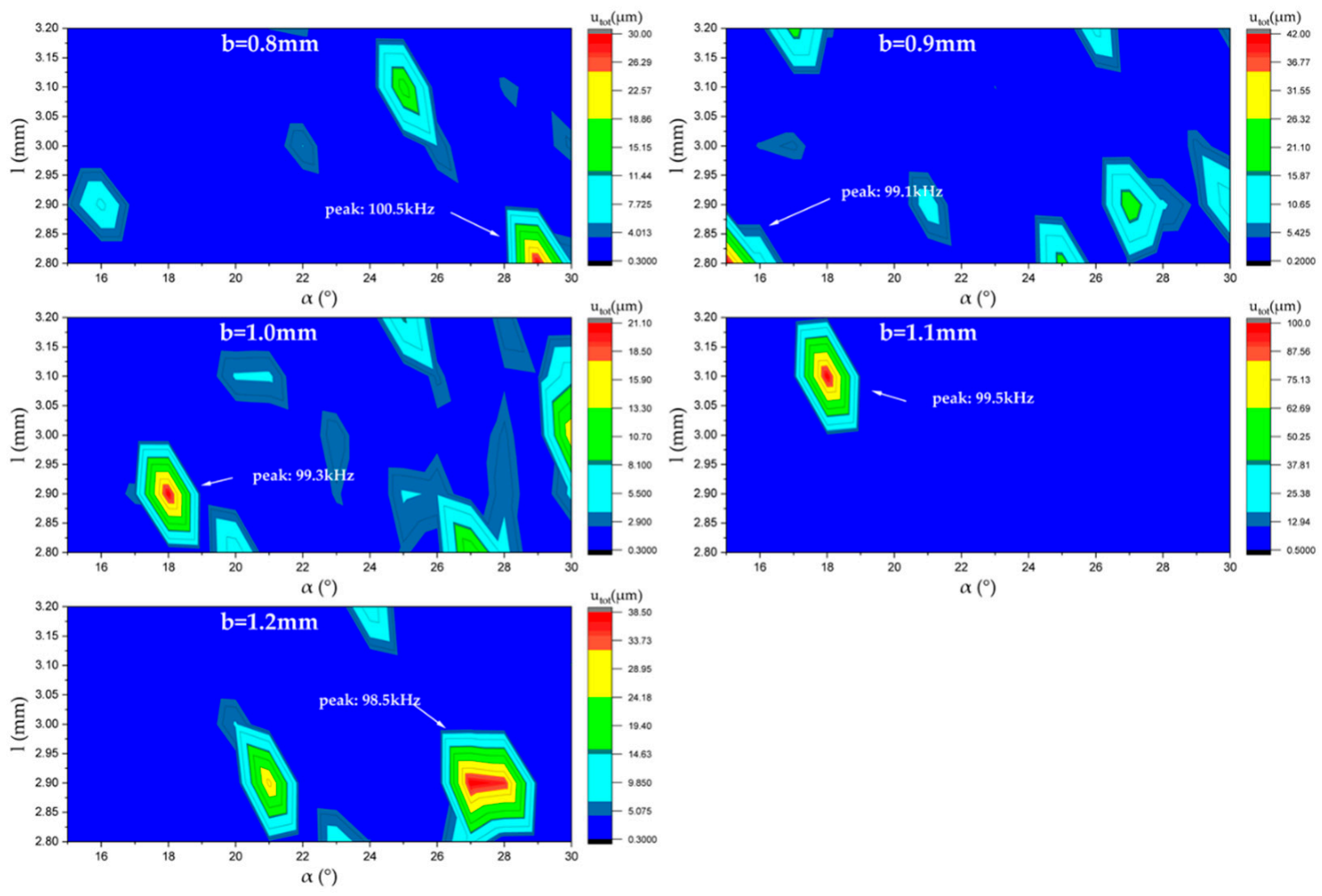

Figure 7. 2D plots of the amplitude of contact points in $\mathrm{B}_{03}$ mode vary with length, width, and angle of contact teeth. 
It is shown that the largest displacement amplitude is realized when $l, b$ and $\alpha$ have the values of $18 \mathrm{~mm}, 1.1 \mathrm{~mm}$ and $15^{\circ}$, respectively. The $B_{03}$ mode shape was obtained at $99.5 \mathrm{kHz}$. Therefore, the aforementioned values of $l, b$ and $\alpha$ were chosen in further numerical investigations. A time domain study has also been performed, to validate the operating principle of the stator. Frequency of the excitation signals was set to $99.1 \mathrm{kHz}$. Analyzed time range was set to one period of excitation frequency i.e., $10.09 \mu$ s with a time step of $1 \mu \mathrm{s}$, which is approximately $1 / 10$ of one period. Figure 8 shows the results of the time domain study. Two phases of one period i.e., the contraction phase and the expansion phase of the stator, are presented.

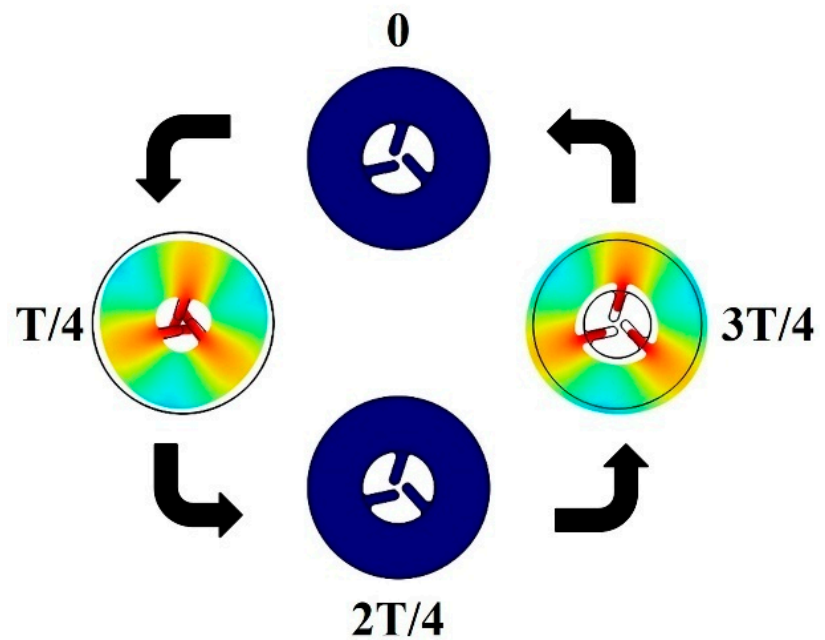

Figure 8. Phases of the stator operation.

\section{Stator Vibration Measurement}

A prototype with optimal dimensions was made and assembled. The resonant frequency of the stator was measured by precision impedance analyzer Agilent 4294A. The result of the measurement is shown in Figure 9. In the graph, the orange line is $|Z|-f$ curve and the blue one is $|\theta|-f$ curve, where $|Z|$ is the impedance of the stator and $\theta$ is the phase shift. The frequency changes from $80 \mathrm{kHz}$ to $120 \mathrm{kHz}$. The lowest point of the $|Z|-f$ curve means that the stator has the lowest impedance at the corresponding frequency, which is $98.128 \mathrm{kHz}$. Therefore, the resonant frequency measured by the impedance analyzer is $98.128 \mathrm{kHz}$. The difference between the measured and simulated frequencies is approximately $0.98 \%$.

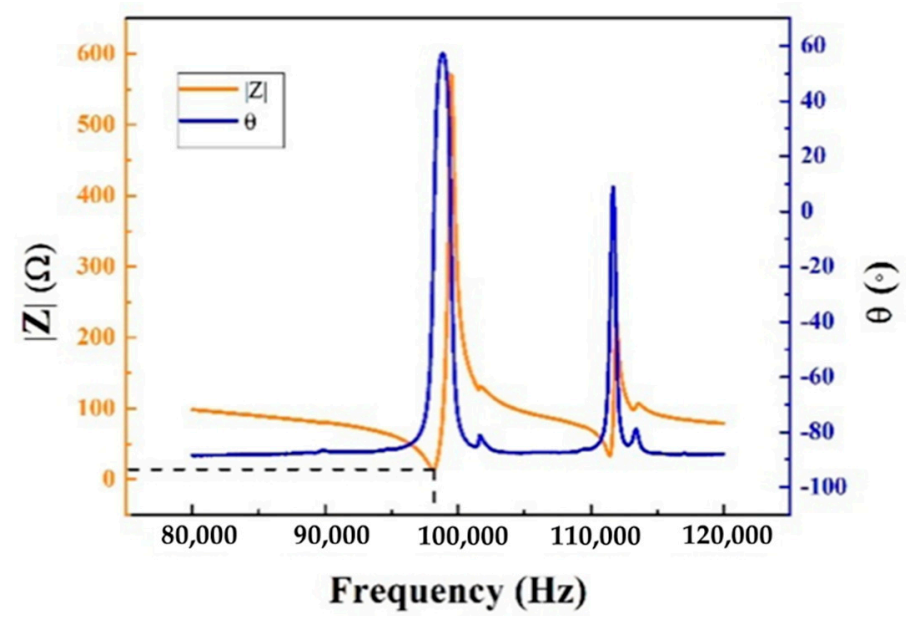

Figure 9. Impedance-frequency characteristics of the stator. 
The vibration mode of the stator was measured by 2D laser Doppler vibrometer, as Figure 10d is shown. The result of the measurement is shown in Figure 10a. It shows that $\mathrm{B}_{03}$ vibration mode is dominant in the vibration shape of the stator, which meet a good agreement with FEM results. Figure 10c shows the resonant frequency measured by laser vibrometer, which is $98.875 \mathrm{kHz}$. The difference between the measured and simulated frequencies is $0.76 \%$. The error between resonant frequency obtained by impedance analyzer and vibrometer is caused by differences in clamping during measurements. Amplitudes in axial direction of the three contact teeth were measured separately, using the trimorph stator disc. The tip of each of the contact teeth was taken to be measured, and the results are shown in Figure 10b. The axial vibration amplitudes of the three points are $14.59 \mathrm{~nm}, 62.62 \mathrm{~nm}$ and $27.24 \mathrm{~nm}$, respectively, at a voltage of $40 \mathrm{~V}_{\mathrm{pp}}$, which confirms that the $\mathrm{B}_{03}$ mode was excited under the test condition and no out-of-plane mode interference was found.

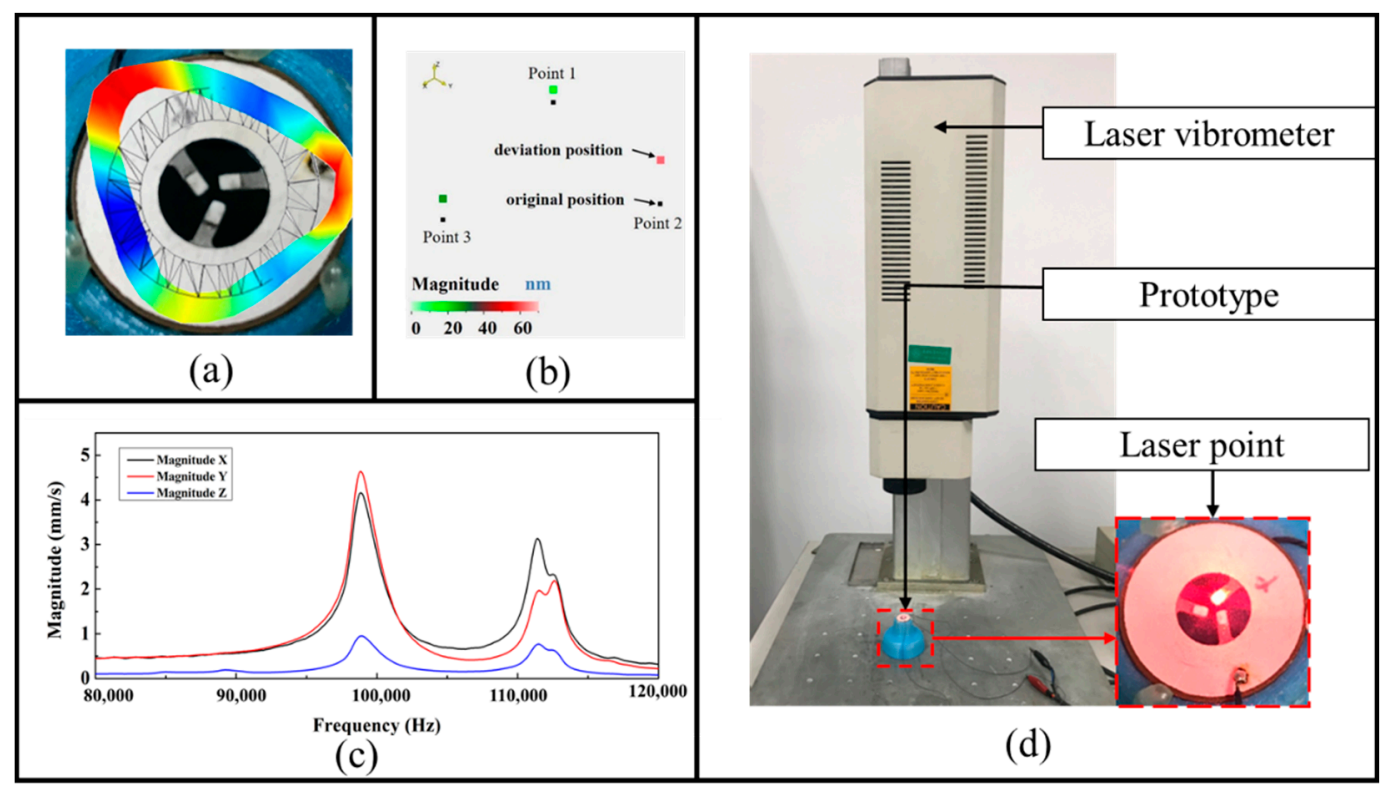

Figure 10. (a) Laser measurement of the stator vibration. (b) Magnitude of the motor contact point. (c) Magnitude-frequency characteristics of the stator. (d) Laser measurement setup.

\section{USM's Output Performance Test}

An experimental investigation was performed, to validate the operating principle and to assess output performance of the motor (Figure 11). A motor prototype was set up into a holder and excited by a single channel of sinusoidal excitation. A laser tachometer was used to record the rotation speed of the motor, when input voltage and frequency changed. Figure 12 shows the relationship between motor driving frequency and rotation speed, under different input voltage. It is apparent that the prototype produces the best output performance under the frequency of $98.5 \mathrm{kHz}$, which verifies the ideal driving performance of in-plane $\mathrm{B}_{03}$ mode. The maximum unloaded rotational speed of the motor reached $5172 \mathrm{rpm}$ when $30 \mathrm{~V}$ was applied.

The ultrasonic motor is generally used in intermittent working situations due to its friction driving principle. Long-term continuous operation of the USM will bring serious friction and wear, which will result in a sudden drop of the performance or even cause it to stop working. The present design is aimed to be used in continuous operation in high rotation speed scenarios, so it is important to reduce the friction and wear, and effectively prolong the working life of the USM. Figure 13a shows the initial surface state of the titanium contact teeth without a protective layer. Figure 13b shows the wear of the contact teeth after six hours of continuous testing, and it is noticed that the teeth surface is seriously worn. To alleviate the performance degradation caused by friction and wear, 
an alumina ceramic cover was pasted on the contact teeth, to extend the service life of the USM. Figure 13c shows the initial surface state of alumina covered titanium teeth before wear, and Figure 13d shows the surface condition of alumina covered titanium teeth after six hours of continuous testing. By comparing the two experimental results, the stator covered with alumina is more wear-resistant than that with no coatings. Moreover, the alumina-alumina contact interface has superior mechanical transmission efficiency than the alumina-titanium contact interface. Figure 14 shows rotation speed changes of the USM versus the operating time between parts with and without alumina coatings. It is indicated that the USM with alumina coated stator teeth has a larger initial output speed of 3321 RPM and a much lower output speed drop of $13 \%$, while the corresponding values of the compared USM which did not have alumina coated stator teeth are $2240 \mathrm{rpm}$ and $88 \%$, respectively. Therefore, the alumina coating layer plays an important role in improving the output performance and working life of the designed ultrasonic motor.

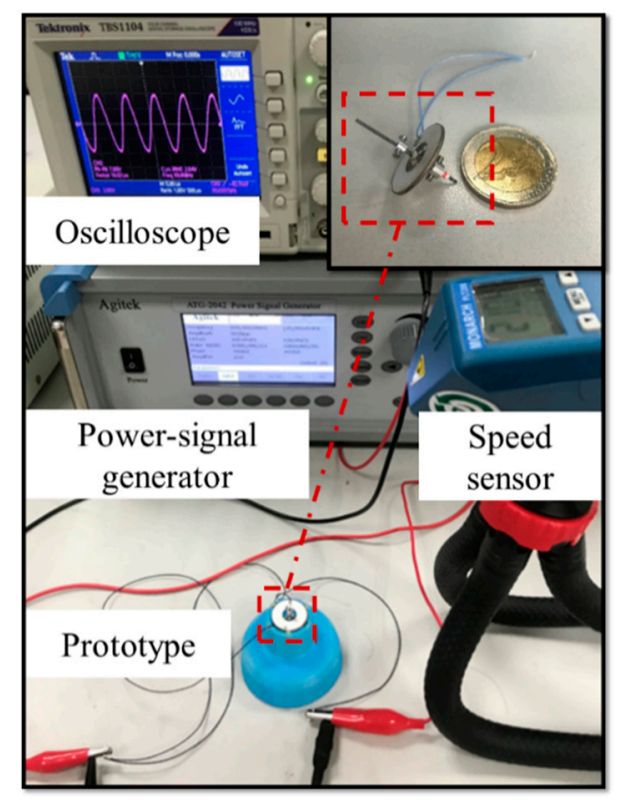

Figure 11. Prototype and experimental setup of the ultrasonic motor (USM).

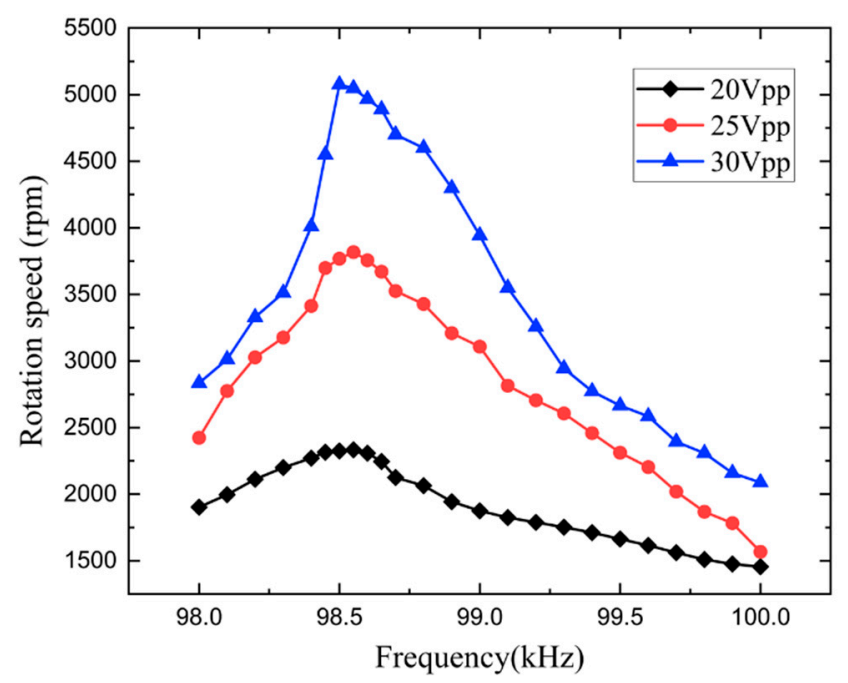

Figure 12. The relationship between driving frequency and rotation speed under different input voltages. 


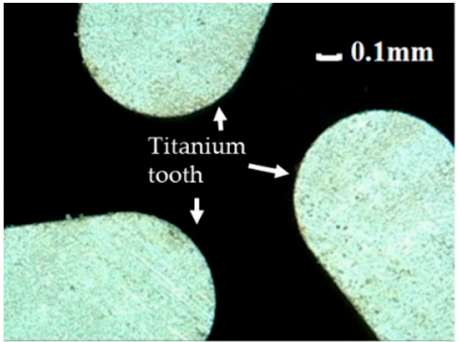

(a)

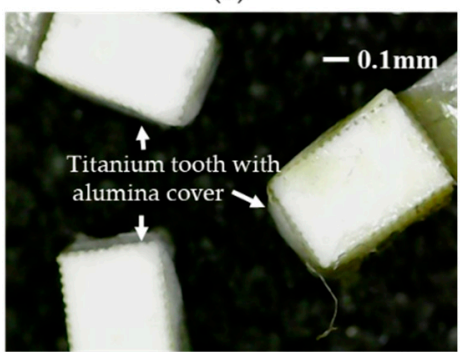

(c)

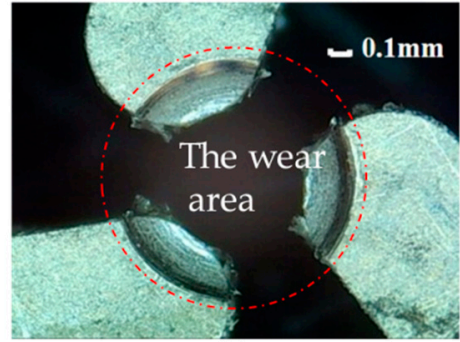

(b)

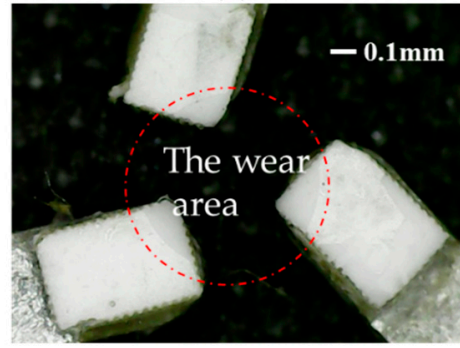

(d)

Figure 13. (a) Surface condition of titanium teeth before wear; (b) surface condition of titanium teeth after wear; (c) surface condition of alumina coated titanium teeth before wear; (d) surface condition of alumina coated titanium teeth after wear.

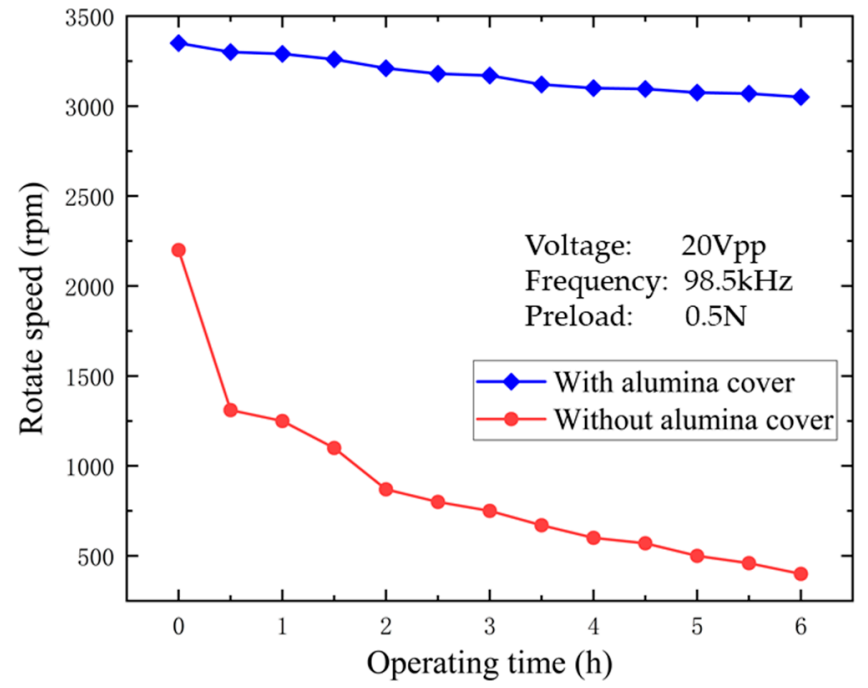

Figure 14. Rotation speed of the USM versus operating time under different contact materials.

Figure 15a shows the response of the unloaded rotational speed, with different preload force. It is found that when the preload is $0.5 \mathrm{~N}$, the USM obtains the highest rotational speed. Figure 16 shows the setup of the stalling torque measurement. The shaft of the USM passes through two bearings which are supported by a holder and connects to a pulley. The diameter of the pulley is $6.4 \mathrm{~mm}$, and the relation between input voltage and stalling torque is shown in Figure 15b. Maximum stalling torque is about $0.35 \mathrm{mN} \cdot \mathrm{m}$ when driving voltage reaches $30 \mathrm{~V}_{\mathrm{pp}}$. The power efficiency of it can be calculated by the following equation after getting the needed parameters:

$$
\eta=\frac{n M_{b}}{9550 u_{i n} i_{i n}}
$$

where $\eta, u_{i n}, i_{i n}, n$ and $M_{b}$ refer to power efficiency, input voltage, input current, USM's rotation speed and stalling torque, respectively. The power efficiency of the prototype can reach $51.5 \%$, which is 2.5 times higher than regular DC motors with a similar size. These 
properties are a big benefit to the MAV power system. This high power efficiency means an energy saving, which will increase the endurance time of the MAV.

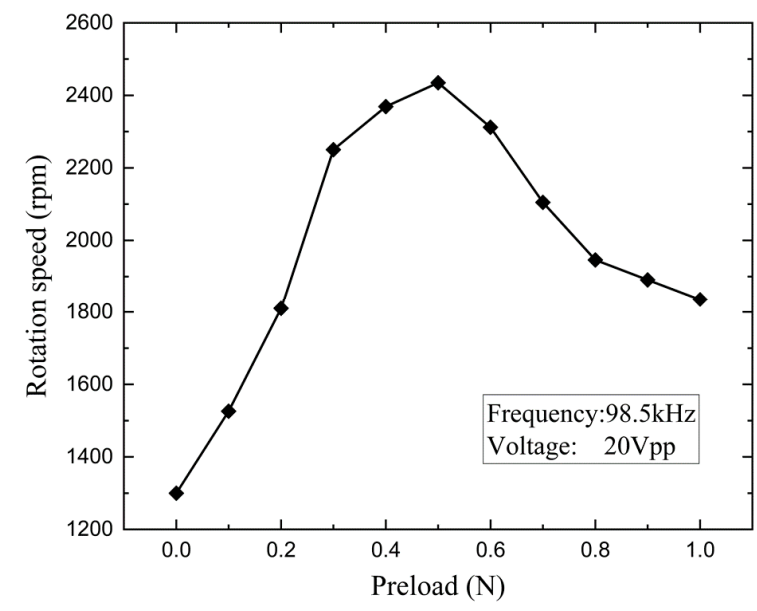

(a)

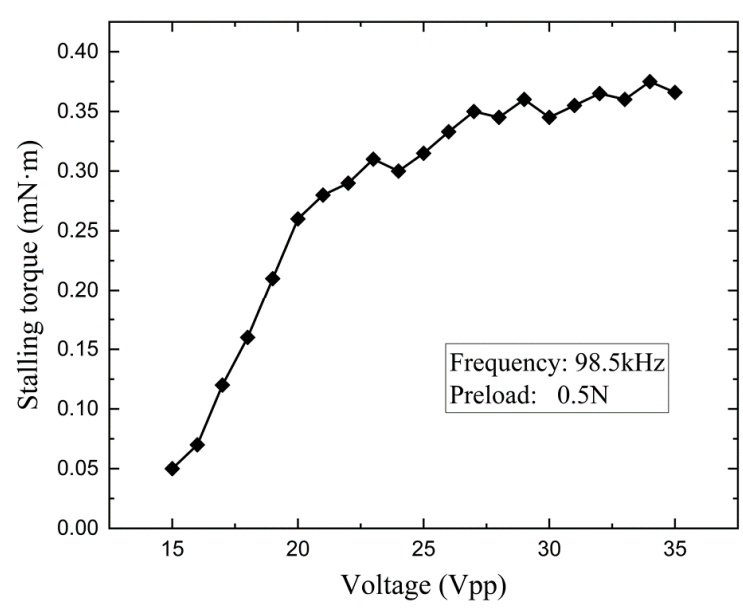

(b)

Figure 15. (a) Rotational speed of the USM versus preload; (b) stalling torque of the USM versus driving voltage.
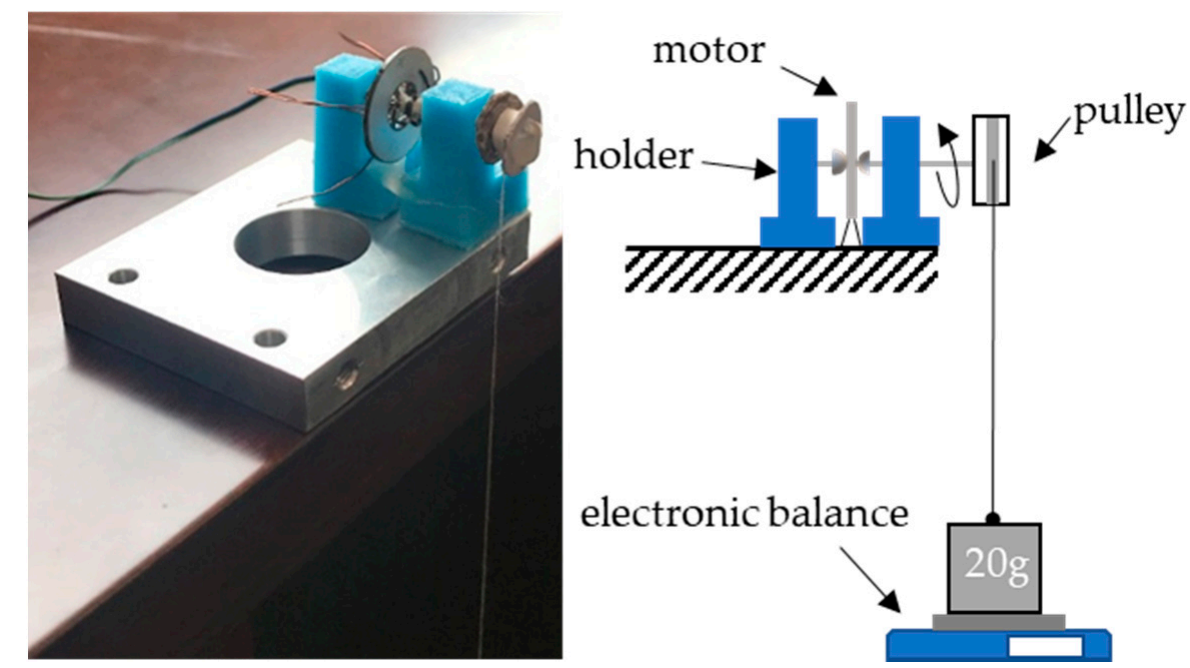

Figure 16. Experiment setup for USM's output measurement.

\section{Test of the USM's Lifting Force}

The experiment setup for the rotor system lifting force measurement is shown in Figure 17. The lift-weight ratios of six different propellers were tested under the input voltage of $20 \mathrm{~V}_{\mathrm{pp}}$, and the result is shown in Table 3. In this table, total mass refers to the mass of the propeller and the USM. The propeller needs to match the load characteristic of the motor to gain the biggest lift force. Propeller no. 6 provides the biggest lift-weight ratios among them. The lifting force of it under different voltage is shown in Figure 18. The maximum lifting force generated by this USM was measured as $46.1 \mathrm{mN}$, which is 2.35 times bigger than its weight. It proves this rotor system is capable to carry additional load. Figure 19 shows a hover flight test result of the piezoelectric rotor system when installed into a linear guide rail, which indicates that the piezoelectric rotor system has good attitude stability. When the drive voltage is close to $45 \mathrm{~V}_{\mathrm{pp}}$, the whole device starts to take off, and when the drive voltage reaches $50 \mathrm{~V}_{\mathrm{pp}}$, the whole rotor system can hover stably in the air. Power consumption of the rotor system was $435 \mathrm{~mW}$. 


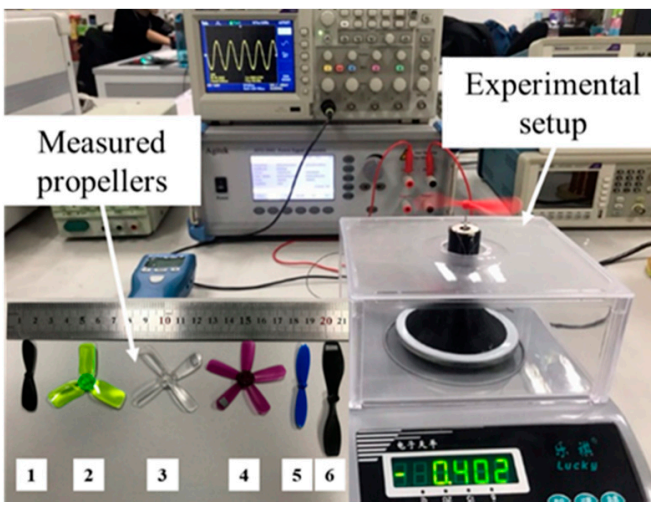

Figure 17. Experiment setup for the test of rotor's lifting force.

Table 3. The lift-weight ratios of different propellers.

\begin{tabular}{ccccc}
\hline Propeller No. & Total Mass/g & Rotation Speed/rpm & Lifting Force/mN & Lift-Weight Ratio \\
\hline 1 & 2.36 & 2145 & 0.245 & 0.0106 \\
2 & 3.17 & 1910 & 0.519 & 0.0167 \\
3 & 2.89 & 2112 & 0.696 & 0.0246 \\
4 & 3.06 & 1879 & 1.303 & 0.0435 \\
5 & 2.4 & 2081 & 0.353 & 0.0150 \\
6 & 2.95 & 1760 & 3.910 & 0.1350 \\
\hline
\end{tabular}

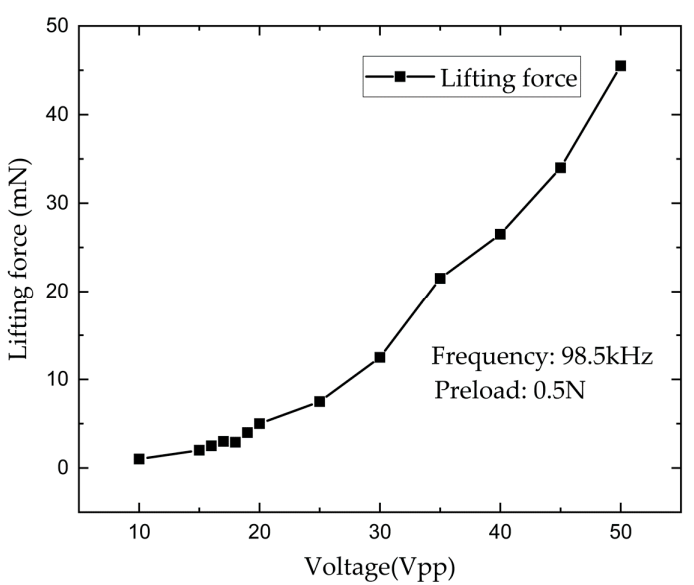

Figure 18. Rotor's lifting force versus driving voltage.

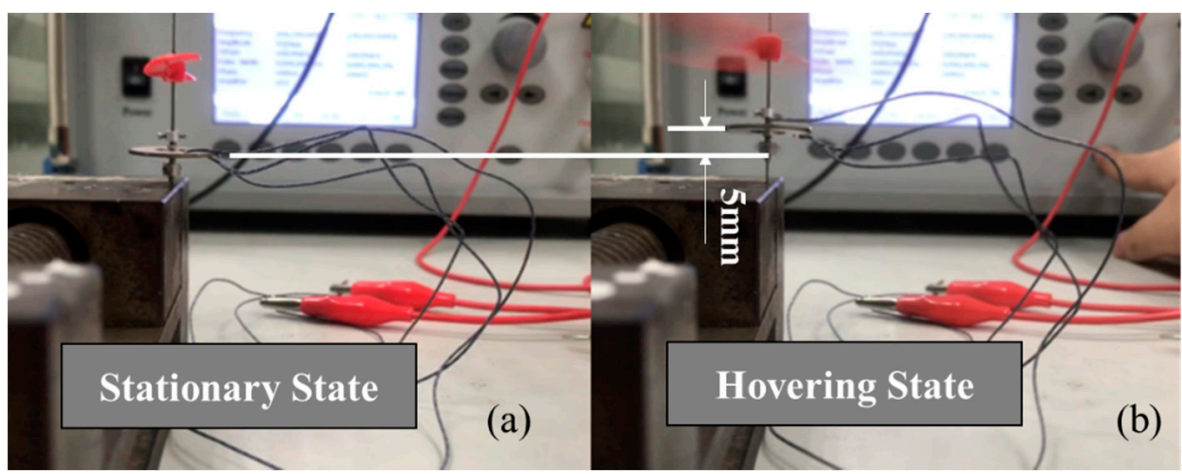

Figure 19. Hover flight test of the piezoelectric rotor system. (a) Stationary state. (b) Hovering state. 


\section{Conclusions}

A disc-type ultrasonic motor with internal contact teeth was developed. The prototype of the designed ultrasonic motor, with optimal dimensions based on the numerical simulation, has been manufactured and assembled. The results of the numerical simulation and experimental study validated the operating principle of the USM. The optimal frequency of the excitation signal and the preload force are $98.5 \mathrm{kHz}$ and $0.5 \mathrm{~N}$, respectively. The driving voltage of the USM is significantly lower compared to most of the existing high-speed rotary ultrasonic motors. The unloaded rotational speed of the USM reaches to $5172 \mathrm{rpm}$ at $30 \mathrm{~V}_{\mathrm{pp}}$ applied driving voltage. The results of this experimental study are in good agreement with the numerical analysis. The lifting force test proves that the USM has good load capacity. The present design of the rotary ultrasonic motor can be used on several different occasions including but not limited to micro air vehicles.

Author Contributions: J.Q. contributed to conceptualization, numerical and experimental investigations and preparation of the paper; Y.Y. contributed to conceptualization, review and editing, supervision, project administration and funding acquisition; X.H. contributed to conceptualization, numerical and experimental studies and preparation of the paper; P.V. contributed to conceptualization and numerical and experimental investigations; D.M. contributed to conceptualization and numerical and experimental investigations; S.B. contributed to conceptualization and numerical and experimental investigations. All authors have read and agreed to the published version of the manuscript.

Funding: This research was funded by National Natural Science Foundation of China, grant number U2037603; The 111 project, grant number B12021; Jiangsu Provincial Science and Technology Project, grant number BZ2020006; The Priority Academic Program Development of Jiangsu Higher Education Institutions.

Institutional Review Board Statement: Not applicable.

Informed Consent Statement: Not applicable.

Conflicts of Interest: The authors declare no conflict of interest.

\section{References}

1. Morita, T. Miniature piezoelectric motors. Sens. Actuators A Phys. 2003, 103, 291-300. [CrossRef]

2. Liu, K.C.; Friend, J. A brief review of actuation at the micro-scale using electrostatics, electromagnetics and piezoelectric ultrasonics. J. Acoust. Soc. Jpn. 2010, 31, 115-123. [CrossRef]

3. Floreano, D.; Wood, R.J. Science, technology and the future of small autonomous drones. Nature 2015, 521, 460-466. [CrossRef] [PubMed]

4. Pines, D.J.; Bohorquez, F. Challenges Facing Future Micro-Air-Vehicle Development. J. Aircr. 2012, 43, 290-305. [CrossRef]

5. Numata, T.; Iwatani, Y. Indoor Hovering Flight of a Micro Helicopter by Markerless Visual Servo Control Based on Phase Correlation. J. Control. Syst. Integr. 2014, 7, 291-296.

6. Ward, T.A.; Fearday, C.J. A bibliometric review of progress in micro air vehicle research. Int. J. Micro Air Veh. 2017, 9, 175682921667067. [CrossRef]

7. Hassanalian, M.; Abdelkefi, A. Classifications, applications, and design challenges of drones: A review. Prog. Aerosp. Sci. 2017, 91, 99-131. [CrossRef]

8. Bermes, C.; Bouabdallah, S. Design of the autonomous micro helicopter muFly. Mechatronics 2011, 21, 765-775. [CrossRef]

9. Bohorquez, F.; Samuel, P. Design, Analysis and Hover Performance of a Rotary Wing Micro Air Vehicle. J. Am. Helicopter Soc. 2003, 48, 80-90. [CrossRef]

10. Koc, B.; Uchino, K. Piezoelectric Ultrasonic Motors. Ref. Modul. Mater. Sci. Mater. Eng. 2000, 6, 651-661.

11. Aphale, S.S.; Bhikkaji, B. Minimizing Scanning Errors in Piezoelectric Stack-Actuated Nanopositioning Platforms. IEEE Trans. Nanotechnol. 2008, 7, 79-90. [CrossRef]

12. Borodinas, S.; Vasiljev, P. The optimization of a symmetrical coplanar trimorph piezoelectric actuator. Sens. Actuators A Phys. 2013, 200, 133-137. [CrossRef]

13. Wang, L.; Lu, X.L. A novel high-speed rotary ultrasonic motor applied to micro air vehicles. Symp. Piezoelectricity IEEE 2017, $17,176$.

14. Mashimo, T. Micro ultrasonic motor using a one cubic millimeter stator. Sens. Actuators A Phys. 2014, 213, 102-107. [CrossRef]

15. Chu, X.; Ma, L. A disk-pivot structure micro piezoelectric actuator using vibration mode B11. Ultrasonics 2006, 44, e561-e564. [CrossRef] [PubMed]

16. Čeponis, A.; Mažeika, D. Flat Cross-Shaped Piezoelectric Rotary Motor. Appl. Sci. 2020, 10, 5022. [CrossRef] 